\title{
Inexpensive Cleanroom for Microfabrication, Microarray Work, and Other Activities Requiring Protection from Airborne Contamination
}

BioTechniques 31:842-846 (October 2001)

\author{
Daniel R. Knapp and Jin- \\ Sung Kim \\ Medical University of South \\ Carolina, Charleston, SC, USA
}

Microfabricated devices including microarrays and microfluidic systems are subjects of increasing interest in a variety of fields (1). The production of these devices requires protection from airborne contamination. Ideally, such work is best carried out in a cleanroom facility, but conventional cleanroom construction can cost several hundred dollars per square foot. A less expensive alternative is the "softwall" cleanroom. A softwall clean room is simply a metalframed tent of heavy vinyl curtains that is continuously supplied with filtered air at the top. The air exits at the bottom via a gap between the curtains and the floor. This type of cleanroom is commercially available from several manufacturers and can be installed in almost any kind of open room space. Typically, the tops of these rooms consist of lighting modules and high-efficiency particulate filter modules. ISO class 100, 1000, and 10000 rooms are available (the number indicating the average particle count per cubic foot of air), with more filter units used per square foot of floor area to achieve cleaner conditions. A lighted softwall cleanroom costs on the order of $\$ 100$ per square foot.

We present here a construction design whereby we produced a softwall cleanroom ourselves at a materials cost of approximately $\$ 10$ per square foot (excluding labor) (2). Key to the low cost was the use of existing room lighting via transparent ceiling panels in place of expensive cleanroom lighting fixtures and the use of a new consumer product air cleaner unit that has recently become available for use in woodworking shops. This type of filter unit is specified to move 850 cubic feet per minute of air with up to $98 \%$ efficiency in removing $5-\mu \mathrm{m}$ particles and up to $85 \%$ efficiency in removing $1-\mu \mathrm{m}$ particles (Delta International Machinery Data Sheet for Model 50-860 Air Cleaner, http://www. deltamachinery. com). As a consumer product, the cost of these air cleaner units is much lower than the cost of conventional cleanroom filter units. The relatively easy and inexpensive method described here to produce a cleanroom environment should facilitate wider participation in the recent expansion of research involving microfabricated devices.

Figure 1 shows a drawing of the $6 \times$ 10-foot softwall cleanroom constructed in this laboratory. The frame was fabricated from locally purchased standard steel material using $2 \times 2 \times 1 / 8$-in square tubing for the posts and $2 \times 4 \times$
$1 / 8$-in rectangular tubing for the horizontal beams. The corner joints were formed by attaching $10 \times 10 \times 1 / 8$-in thick triangular steel plates to the posts and beams with 3/8-24 machine screws via threaded holes in the beams.

The sides of the frame were covered with curtains of 0.04 in transparent polyvinyl chloride (PVC, cut from 54-in wide roll material; AIN Plastics, Marietta, CA, USA) attached to the beams with 10-24 machine screws and washers. The curtains were overlapped 6 in at the edges (no sealing was required; the material "sticks" to itself), and a 6-in gap was left between the bottom of the curtains and the floor. A $2 \times 4$-foot entrance vestibule (under the air cleaner unit in Figure 1) was formed in the corner of the enclosure with additional PVC curtains and fitted with a "sticky mat" (Fisher Scientific, Pittsburgh, PA, USA). Air was not supplied to this vestibule. Passages were provided in the ends of the vestibule as overlapped joints between two curtain pieces. The entrance vestibule provides a place for the operator to put on cleanroom apparel (hair cover, frock, and shoe covers; Kappler USA, Guntersville, AL, USA) before entering the cleanroom.

The top of the enclosure was framed with standard ceiling grid material (Armstrong World Industries, Lancaster, PA, USA) screwed to the beams in a pattern to accept $2 \times 4$-foot transparent acrylic ceiling panels (ICI Acrylics, Cordova, TN, USA), which were held 
in the place with clear silicone sealant (RTV; Dow Corning, Midland, MI, USA). The transparent ceiling panels admit room light from yellow fluorescent lamps (General Electric F40GO; Grainger Industrial Supply, Atlanta, GA, USA) mounted in the laboratory light fixtures ("safe lights" for the photosensitive resist). A woodworking shop air cleaner (model 50-860; Delta International Machinery, Pittsburgh, PA, USA) was mounted on the top of the frame, and the effluent was directed via a 12-in diameter flexible duct to a ceiling air diffuser located in the top center of the cleanroom (the duct and diffuser were both purchased locally from an air conditioning supply company).

The cleanroom houses a 4-foot class 100 clean bench (Labconco Purifier; Labconco, Kansas City, MO, USA) and a $30 \times 72$-in stainless-steel worktable purchased from a local restaurant supply vendor. A small fume hood for removal of photoresist solvent vapors during baking was constructed from a 5-gallon, cube-shaped, heavy-duty polyethylene carboy by cutting away the bottom and part of one side. Fumes were removed by attaching a small blower to the carboy spout via 3-in PVC plumbing pipe and exhausting into the laboratory fume hood.

Lacking an on-campus microfabrication facility, we attempted to begin mi- crofabrication work in our laboratory using a class 100 clean bench in a normal laboratory environment. We encountered problems with particulate contamination because all operations could not be kept within the clean bench. The project budget did not include funds to purchase a softwall cleanroom, so we sought a less expensive solution and designed the cleanroom described above. Construction of the cleanroom required about 30 man-hours for painting and assembly of the frame, cutting and attachment of the curtains, and assembly of the ceiling and air cleaner ducting. The major task in building the cleanroom was making the steel frame. Although the least expensive method for making the frame is to fabricate it from steel tubing, laboratories lacking the capability to do this could alternatively construct the frame from commercially available heavy-duty storage rack components [e.g., Tennesco Heavy Duty Bulk Rack (Grainger Industrial Supply, Atlanta, GA, USA) or comparable bulk rack components from McMaster Carr Supply, Atlanta, GA, USA].

Major cost factors in commercial softwall cleanrooms are the ceiling lighting units and the filter units. We eliminated the lighting cost by simply using transparent ceiling panels to admit room light from the laboratory, which had already been fitted with yel-

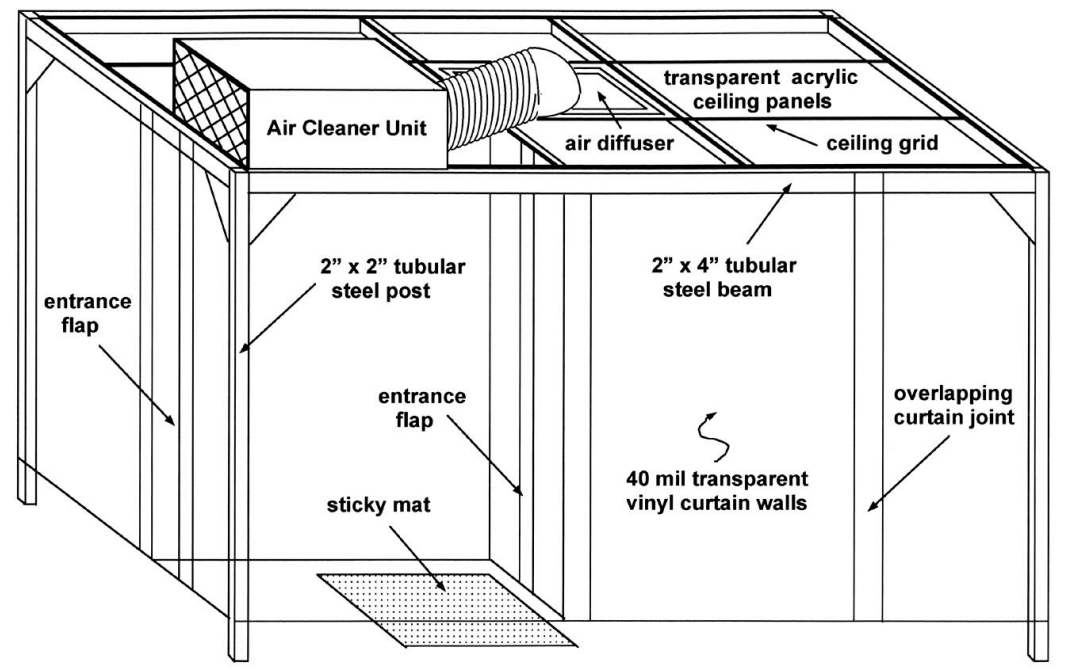

Figure 1. Drawing of the softwall cleanroom. low fluorescent tubes in the existing ceiling fixtures as safelights for photoresist (the light fixture in the clean bench was also changed to a yellow tube). We reduced the filter unit cost by using a recently available air cleaner unit sold for use in woodworking shops. The air cleaner was located over the vestibule so as not to block light through the ceiling panels to the working area. Our available laboratory floor space dictated the $6 \times 10$-foot size, which accommodates a 4-foot filtered air class 100 clean bench and a 6-foot worktable and provides adequate workspace for one operator. This cleanroom eliminated the particulate contamination problems we had encountered in making microfluidic devices using soft lithography (3) methods.

This cleanroom has been certified as ISO class 10000 by an independent testing company (Certification Testing, Loganville, GA, USA). ISO class 10000 is often the specification used for general space in conventional microfabrication facilities (which would have cleaner areas within the general facility). Actual measurements of 0.5$\mu \mathrm{m}$ and larger particles within the room ranged from approximately 500 near the front of the clean bench to approximately 10000 near the center of the room and approximately 16000 in the corners distant from the clean bench. The measurements were taken after several days of continuous operation of the air cleaner. Since we operate the air cleaner continuously, it is not clear how long it would take to reach class 10000 conditions if used intermittently. The clean bench operating within the room undoubtedly contributes to reducing the particle count; it is not known whether this room could achieve class 10000 without the clean bench. Commercial softwall clean rooms achieve lower particulate counts by adding additional filter units. Therefore, using more than one filter unit could likely reduce the particle count in our cleanroom, although more filter units would reduce the light within the room by covering ceiling panels. It should also be noted that the air cleaner unit used in this design was not rated for $0.5-\mu \mathrm{m}$ particles, the lower-limit particle size used for certification.

Installing a softwall cleanroom in a 
laboratory raises certain safety issues. The PVC curtain material used for the cleanroom walls meets the National Fire Protection Association 701 Flame Test Criteria and was therefore approved for laboratory installation by our institutional occupational safety and health program fire marshal. The acrylic ceiling panels are made for ceiling construction and, thus, were also acceptable. There was need to exhaust solvent fumes from baking photoresist on a hotplate inside the room; this was achieved by improvising a small fume hood from a plastic carboy. Our cleanroom was deemed by the safety inspector to be a separate room without a safety shower inside; thus, we are prohibited from using corrosive chemicals within the room.

The cleanroom described here has proven to be an inexpensive solution to providing a low airborne particle count environment for fabrication of microfluidic devices on a campus without a con- ventional microfabrication facility. This design could also be used to inexpensively provide more convenient cleanroom facilities, even where a conventional facility exists. We hope that making others aware of our approach will facilitate microfabrication work where it might otherwise not be feasible.

\section{ACKNOWLEDGMENTS}

We thank C.H. Harvey and J.R. Francis for their efforts in construction of the cleanroom. This work was supported by National Science Foundation grant no. DBI 9906662.

\section{REFERENCES}

1.Figeys, D. and D. Pinto. 2000. Lab-on-aChip: a revolution in biological and medical sciences. Anal. Chem. 72:330A-335A.

2.Kim, J.S. and D.R. Knapp. 2001. Microfab- ricated PDMS multichannel emitter for electrospray ionization mass spectrometry. J. Am. Soc. Mass Spectrom. 12:463-469.

3.Xia, Y. and G.M. Whitesides. 1998. Soft lithography. Angew. Chem. Int. Ed. 37:550-575.

Received 30 April 2001; accepted 9 July 2001.

Address correspondence to:

Dr. Daniel R. Knapp

Department of Pharmacology

Medical University of South Carolina

173 Ashley Avenue

Charleston, SC 29425, USA

e-mail: knappdr@musc.edu

For reprints of this or any other article, contact Reprints@BioTechniques.com 